\title{
Analysis on Outlook on Life of Contemporary University Students
}

\author{
Haiyan $\mathrm{Wu}^{1} \&$ Lin Ding ${ }^{1}$ \\ ${ }^{1}$ College of Politics, Sichuan Agricultural University, Ya'an, China \\ Correspondence: Lin Ding, College of Politics, Sichuan Agricultural University, 46 XinKang Road, Ya'an \\ 625014, Sichuan, China. Tel: 86-187-2816-2046. E-mail: 449697086@qq.com
}

\author{
Received: August 1, 2012 Accepted: August 23, 2012 Online Published: November 30, 2012 \\ doi:10.5539/ass.v8n15p62 URL: http://dx.doi.org/10.5539/ass.v8n15p62
}

\begin{abstract}
Outlook on life, forming in practice, is the fundamental view on life purpose and life meaning and it determines the objective of people's practical activity, the direction of life path and the attitude towards life. From four aspects (life purpose, life ideal, life value and life attitude) which are the basic content of outlook on life, the thesis analyzes the current situation of outlook on life of contemporary university students in China and the situation contains the mainstream and problems, then, it studies to a certain extent the causes of the problems, finally, it proposes the countermeasures about how to educate their outlook on life, namely, how to guide them to establish scientific life purpose, life ideal, life value and life attitude, ultimately, to help them to form and build positive outlook on life.
\end{abstract}

Keywords: university students, outlook on life, education

\section{Introduction}

With in-depth development of China's socialistic market economy, the elements of social economy, the forms of organization, the means of obtaining employment, the interest relations and the ways of allocation have been increasingly diversified, meanwhile, the independence, electiveness, variability and difference of people's ideological activities are increasingly heightened. On one hand, it helps university students to form awareness of self-improvement, innovation, accomplishment and entrepreneurship, on the other hand, it also brings some negative impacts which can not be ignored. To varying degrees, there exist some issues about outlook on life of university students, such as fuzzy ideals and beliefs, distorted value orientations, insufficient social responsibility, diluted spirit of arduous struggle, poor mental quality and so on. Contemporary university students are the future of China and the hope of Chinese nation, whether they can form scientific outlook on life directly concerns the success or failure of the cause of socialism with Chinese characteristics and the great rejuvenation of Chinese nation. Therefore, it is great meaningful to make an in-depth analysis on the current situation of contemporary university students' outlook on life and enhance their education of outlook on life.

\section{Current Situation of Contemporary University Students' Outlook on Life}

\subsection{Analysis on the Mainstream}

Overall, being positive is the mainstream of contemporary university students' outlook on life. Specifically, it includes the following aspects.

Firstly, contemporary university students have proper and explicit life purposes which basically meet the requirements of society and times. According to some relevant statistics, there were about 70000 volunteers in Beijing Olympic Games in 2008 and about 30000 volunteers in the Paralympic Games, it is worth mentioning that almost all the volunteers are university students; during World Expo in 2010, more than 200 million people joined the volunteer team and university students accounted for $90.6 \%$ of all the members. For the question "what kind of person are you willing to be", university students giving such answers as 'succeeding in a special field of study and serving the motherland' and 'serving the people wholeheartedly' account for $72.9 \%$ of investigation number, a large proportion of them would like to be "socialist builders" and "law-abiding citizens" and they concern about the success of career, happiness of family and profound knowledge.

Secondly, most contemporary university students have life ideals and beliefs, positive attitudes towards life and learning and confidence in the development of national various undertakings, keep a watchful eye on the future of our motherland and infinitely long for their own future development. Vast majority of them approve of or 
accept communist ideal, more and more university students actively apply to join the Communist Party of China, strive for excellence in all aspects and try hard to move closer to the party. Some of them finally establish the lofty ideal of communism and the common ideal of socialism with Chinese characteristics and are ready to fight for these ideals in their whole life.

Thirdly, contemporary university students have basically correct life values and they can deal well with the relationship between "dedication" and "obtainment". Their life values are mainly about "how much contribution you can make to society" and "success or failure of personal career". They pay attention to personal development and whether their outlook on life matches with their strengths and income.(Zhu Qiufei, 2010) After Wenchuan Earthquake( May, 12, 2008), with their passion, university students saved the lives of compatriots in disaster areas; inside and outside the stadium of Beijing Olympic Games, they went around in the hot sun and smiled in the heavy rain, with their enthusiasm, sincere and good service, they won the dignity and friendship for our country; in the procession phalanx which was to celebrate the 60th anniversary of the foundation of New China, they took a heroic posture and highlighted the unique glamour. Hong Zhanhui, took along his "younger sister" (the abandoned girl) to go to school and kept such an action for 12 years; Xu Wei, jumped into the ice cave to rescue people; Zhou Shu, had cared for the lonely old for 12 years and considered it as her obligation; Huang Bihai, wake up his vegetative mother with love, all of the above show that more and more young university students move China and erect a benchmark of good value concept in people's minds.(Li Yaoming \& Gao Liang, 2012)

Fourthly, life attitudes of contemporary university students mostly are "being positive, optimistic and enterprising" and "being satisfied with the status and doing something based on one's capability", what they care most is the sense of responsibility, diligence, honesty and integrity; the majority of university students are able to correctly understand the difficulties and frustrations appearing on their life road, in their opinions, encountering difficulties is an inevitable step to achieve life goals and most difficulties will be overcome if they work hard. There are also some university students who believe that one must have the courage to challenge difficulties and the courage is still commendable even if he fails. Such rational cognitions will ensure that they can keep tenacious, confident and impassioned on their road of life pursuit.

\subsection{Analysis on Problems (Tributary)}

"Serving the people" is not the life purpose that some university students have established. Instead, their awareness of serving the people is very weak. Part of them treat people's interests as an empty fiction and give more consideration to their personal interests with little or no consideration to the interests of people, naturally, "severing the people" has become an empty phrase. Among a small number of university students, it even appears a thought tendency that negating the idea of "serving the people" and few of them think the idea is out of date. Most university students will serve the people and make contribution to society if their own interests are not influenced; however, once their own interests are involved, many students only value individual interests, put collective interests and people's interests on the secondary position or forget to serve the people.

Some university students have fuzzy life ideals so that some words such as "meaningless" ,"boring" and "confused"can often be heard. They have lost life direction at the beginning of university life and then they waste time every day, in addition to sleeping, they usually chat and play games on the Internet, so there is no basic rhythm at all in their life and the school work is also deserted. Besides, the positioning level of their life ideals is not so high, for instance, $47.7 \%$ of university students think comfortable life and pleasure is the greatest success of life, moreover, $37.5 \%$ of them consider "to glorify and illuminate the ancestors", "to be famous persons" and "to be the rich" as their life goals. Such survey results at least illustrate two points. First, a considerable portion of university students take the pursuit of personal life enjoyment as their supreme life ideal and their understanding of the meaning of life is too secular; second, a considerable part of them do not associate the achievement of life value with the dedication to motherland and society or the association is not tight enough. (Jing Yuting, 2009)

In the aspect of life value, some university students overly concern about the realization of self-value but ignore the social value of life. In the aspect of value orientation, there is a self-involved tendency, namely, they only emphasize self-demand without taking contribution to society seriously; in the aspect of value cognition, there exists a tendency of contradiction, in other words, in theory, they do not deny the significance of making contribution to society, but once they meet practical issues, there is merely self left, that is, they only emphasize individual needs and personal interests but pay no attention to dedication they should make to the community; moreover, they are very concerned with immediate material interests without making long-term plan for life development; in the aspect of value realization, they have an utilitarian tendency. 
In the respect of life attitude, not a few university students have poor mental endurance; when they face the pressure of family poverty, examination failure, love failure and so on, they often become confused, generate anxiety, irritability, pessimism and other emotions and even lose confidence in life and make extreme behavior. Some of them think that the momentary difficulties can not be conquered by themselves, under the influence of despair mentality, they will lose interest in all objects around, care for neither their own things or others, shut themselves up and be unwilling to associate with others, at last, they may have a series of psychological problems.

\section{Analysis on Causes of the Problems}

\subsection{About Life Purpose}

Under the conditions of the current market economy, interests present a diversified and individualized trend, which shelters and weakens the interests of people and the overall. Although vast majority of university students keep an eye on the future and destiny of the country, nation and people, hope to serve the motherland and people and acknowledge and approve that they should have lofty social ideals and put their talents and wisdom into the great social practice of serving the people, however, on the specific choice, their behavior deviates from their cognition. Many of them make pragmatic and even utilitarian choice, thirsting for a life of ease, comfort, smoothness, no worry and rich material enjoyment, lack of the spirit of arduous struggle, therefore, it is difficult for them to "serve the people wholeheartedly".

The advent of era of knowledge-driven economy has changed the mental outlook of university students in many ways including modes of thinking, concepts of culture and styles of life. The rapid development of modern science and technology, especially the development of network technology, has increased the material wealth of society, broadened students' living space and changed their quality of life, nevertheless, at the same time, it is also easy to make university students emerge a tendency of advocating material power, underestimating spiritual power, pursuing material creation and ignoring cultivation of morality, in a word, Marxism scientific life purpose is challenged to a certain degree.

\subsection{About Life Ideal}

At present, the international communism movement is in a low ebb, so is the cause of socialism, consequently, it turns up a thought trend of denying socialism in the international arena. Simultaneously, a thought trend of denying Marxism still exists, which is a challenge to China (a socialist country sticking to Marxism as the guiding ideology) and it influences university students' understanding of Marxism and makes their ideology, ideals and beliefs confused and lost.

Additionally, some local authorities and schools pay insufficient attention to education of ideals and beliefs of university students and the educational methods are also very limited. The social environment is becoming more and more complex while the composite force that caring about education of ideals and beliefs of university students in the whole society has not yet formed. Ideals or ambitions that they accept at school will often be in total disintegration once they meet complex reality. Nowadays, education of ideals and beliefs does not tightly link with the thought reality of university students. Too much emphasis is put on instilling ideals and beliefs while education of how to guide them to be surefooted, to start from simple things and to begin doing things right now has been neglected. It makes education inadvertently transformed into political preach, which contributes to the generation of reverse psychology. (Han Zhen \& Zhang Xiangyun, 2005) These factors are not conducive for contemporary university students to foster and establish right life ideals.

\subsection{About Life Value}

Modern China is in the period of social reform and transition. The conflict between traditional and modern concepts and the blending and confrontation between western and eastern cultures result in that social values present diversified situation. Since values appropriate to times have not yet formed and traditional values have not taken effect fully, coupled with the impacts of various negative trends of thought, life values of some university students incline to be "selfish", what's worse, their values are distorted by "money" and presents an "utilitarian" and "vulgar" tendency. Equivalent exchange of commodity economy is a principle of market economy, but some university students mistakenly regard it as a criterion of thought and behavior, which causes such phenomena as doing things for money, making devotion for obtainment and measuring their behavior with "equivalent exchange".

Furthermore, the majority of contemporary university students are "the only child" of their family, due to superior financial situation, they have never gone through the hoops of hard life. At home, they are often coddled as "little emperors" by parents so that they easily form selfish and arrogant mentality which makes many of them 
inevitably have various problems on the orientation of life value. For example, only seeking for obtainment, neglecting dedication, being eager for quick success and instant benefits, loving ease but hating working, relaxing in learning, being self-concerned, refusing to devote, possessing vulnerable consciousness of dedication, being afraid of hard work, coveting a life of hedonism, admiring vanity and pursuing high consumption. (Ma Xiangzhen, 2007)

\subsection{About Life Attitude}

Contemporary university students were mostly born in the 1990s, this generation have richer social cognition and become more rational. From the outset, some of them have set specific objectives such as passing CET(college English test) and other exams for certificates and obtaining requested credits, aim at preferably adapting to society in future. These goals put more emphasis on interests and needs at the present stage, lack of long-term, valuable link and integration and ultimate concern for life and society. Because of the absence of this spiritual mainline, university students will be unsure which target to reach in a variety of pursuits, then, it is easy for them to fall into a mental state of anxiety, depression, perplexity and confusion. Once they meet dilemma and find no job, some of them will suspect the significance of going to university and struggling in life and will make periodical loss as the loss of entire life. (Zeng Jing, 2011)

Due to burning in "one-child" family, contemporary university students have quite superior and favored growth environment; they have excessively spoiled by their parents and other elders since childhood, so plenty of them have never tasted a hard life or undergone tough exercise. All of these make their adaptive capacity very poor, after entering into university, they often can not understand the society's complexity completely and their thought seems simple and naive, therefore, it is hard for them to improve and dispose various interpersonal relationships harmoniously and their adaptability and communicative ability are relatively weak. Besides, they are short of strong willpower, being afraid of various setbacks in life, lack of the ability to live independently, hence, they will form a negative and pessimistic life attitude easily.

\section{Corresponding Educational Countermeasures}

Being positive is the mainstream of contemporary university students' outlook on life and it meets requirements of the development of times and society and also benefits their personal sound development. Nonetheless, some problems should not be overlooked, for instance, fuzzy ideals and beliefs, distorted value orientations, negative and pessimistic life attitudes and so on, after making a preliminary discuss on the reasons of the above issues, in order to suit the remedy to the case, some educational measures are proposed.

\subsection{To Strengthen Education of People-orientation Concept and Guide University Students to Establish Proper Life Purpose}

To cultivate scientific, sound and positive life values of university students is the foundation of educating their people-orientation concept. Let them know that the meaning of life lies not only in living for individuals but living for the community and the pursuit of life should include not merely personal wealth and status but the people's well-being and happiness. University students should understand the relationship between personal values and social values and that personal values will make sense only if they display social values in the process of serving the people. The motivation of their life struggle should be based on the theme of serving the people and their personal happiness will get the greatest satisfaction in the pursuit of people's welfare. Through the activities of supporting education in the poor mountainous areas and other youth volunteer activities, university students' spirit of serving the people and awareness of dedication will be gradually fostered. (Sun Hongyan \& Guo Wei, 2011)

\subsection{To Strengthen Education of Ideals and Beliefs and Guide Contemporary University Students to Set Lofty Life Ideal}

Ideal and belief is the banner of ruling the country for a political party, the guide of struggling forward for a nation, the reliable guarantee of keeping forgoing ahead for the cause of socialism and the spiritual pillar and power source of striving for the young people with aspirations. So it is necessary to unequivocally enhance education of ideals and beliefs of contemporary university students, aim at settling some problems such as confused political beliefs, fuzzy ideals and beliefs, strong utilitarian desire, be prone to engendering feeling of inanity and so on. Specifically, it must rely on learning Marxism theory and arming the minds of university students with scientific theory, so that they can really establish scientific beliefs of Marxism. Only in this way, university students are able to remain sober-minded, identify the forward direction and ensure that they will not hesitate, befog and shake their ideals and beliefs at any time; moreover, they will consciously and closely associate personal achievement with the prosperity of the country and even the liberation of all mankind, serving 
the motherland, contributing to society and creating a valuable life. (Zhang Mei, 2010)

\subsection{To Strengthen Education of Socialist Core Values and Guide University Students to Establish Correct Life Value}

It is a key issue which concerns the success or failure of our socialist construction, the future development of our country and the realization of university students' life value that whether young university students can consciously integrate the realization of life value into the great action of achieving the comprehensive rejuvenation of Chinese nation or not.

From the point of Marxism, people's sociality determines that life's social value is the most basic content of life value and how does the society judge a person' value mainly considers his social contribution as the standard. The socialist core value system is a value system that dominates the thinking and behavior of all members of society. Such value system involves economy, politics, culture, society and other aspects of social life and it is the essential reflection of socialism ideology and the ideological and theoretical foundation of the construction of socialism ideology and ethic. (Tan Deli, 2009) Under the conditions of economic globalization, how to educate university students' life value? It must unequivocally adhere to the socialist core values, leading diversified social thoughts with the socialist core value system and maintaining moderate tension between the dominance and diversity in order to help university students to make their direction clear, step out of confusion and reach the higher realm of survival. (Mei Ping \& Liang Mingming, 2011)

\subsection{To Strengthen Education of Life Attitude and Guide University Students to Establish Correct Attitude towards Life}

Hu Jintao placed hope on contemporary youth and put forward some requests to them, he pointed ou that "contemporary youth need to shoulder the noble responsibility entrusted by times, see the situation clearly, have the courage to face any difficulties and obstacles and withstand various ordeals; the development of our country is faced with both rare historical opportunity and severe challenge. Our country will also encounter many complex situations and difficulties on the road ahead and everything will not be so smooth. Young people should learn to look at the situation with a holistic, dialectic and evolutive view. It is wrong and harmful either you only see the bright side, neglecting the difficulties or you underestimate difficulties, keeping blind optimistic. Being afraid of difficulties, shaking confidence and doing nothing are also incorrect and harmful. (Hu Jintao, 1999) Now over ten years have past, for contemporary university students, what Hu Jintao said still has a very important value and a significant enlightening meaning on how to establish scientific and right attitude towards life.

Besides, universities had better organize students to participate in social practice in the poor mountainous areas so that they can live and work with local farmers and appreciate the hardships of life; colorful youth volunteer activities also should be organized to chasten their will, help university students to learn how to bear strike in setbacks and how to deal with various difficulties in life, improve their adaptive ability and cultivate their volitional quality of resisting frustrations.

\section{Conclusion}

University stage is a critical period for university students to form and develop their outlook on life, during this period, whether they can establish scientific outlook on life is directly related to the development of their future life and the prospect and destiny of their motherland. Hence, it is very important and necessary to bring up corresponding education countermeasures to solve some issues about outlook on life of contemporary university students in China.

\section{References}

Han, Z., \& Zhang, X. Y. (2005). Making use of the theoretical advantage of social science, to improve education of ideals and beliefs. China Higher Education, (10).

Hu, J. T. (1999). To carry forward the great spirit of patriotism and work hard for the construction of socialism with Chinese characteristics: Speech at the 80th anniversary conference of May Fourth Movement. People Daily, May 5.

Jing, Y. T. (2009). Investigation and analysis on the current situation of university students' outlook on life and national outlook. Heilongjiang Researches on Higher Education, (8), 148.

Li, Y. M., \& Gao, L. (2012, July 5). University students' ideological and political education: To set foot on a new starting point about how universities work together to educate students. China Education Newspaper, p. A4. Retrieved from http://www.jyb.cn/high/gdjyxw/201207/t20120705_501460.html 
Ma, X. Z. (2007). Analysis on characteristics and their causes of life value of contemporary university students. Mao Zedong and Deng Xiaoping Theory Research, (8), 39.

Mei, P., \& Liang, M. M. (2011). Survey and enlightenment on the situation of life faith of university students. Ideological Education Research, (5).

Sun, H. Y., \& Guo, W. (2011). Education of people-orientation concept and shaping of contemporary university students' life value. School Party Building and Ideological Education, (3), 96.

Tan Deli. (2009). Diversification of value orientation of Contemporary University Students and dominance of core value system. School Party Building and Ideological Education, (7).

Zeng, J. (2011). Research on contradictoriness characteristics of ideals and beliefs of university students born in 1990s. School Party Building and Ideological Education, (6), 54.

Zhang, M. (2010). Study on the status and function of education of ideals and beliefs in University Students' ideological and political education. School Party Building and Ideological Education, (6), 33.

Zhu, Q. F. (2010). Empirical study on outlook on life of university students in different periods. China Youth Research, (8), 70. 